\title{
ASO Visual Abstract: Lymph Node Evaluation following Neoadjuvant Chemotherapy in Patients with Gastric Cancer
}

\author{
Adrienne B. Shannon, MD ${ }^{1}$, Richard J. Straker III, MD' ${ }^{1}$, Luke Keele, PhD $^{1}$, Douglas L. Fraker, MD $^{2}$, \\ Robert E. Roses, $\mathrm{MD}^{2}$, John T. Miura, $\mathrm{MD}^{2}$, and Giorgos C. Karakousis, $\mathrm{MD}^{2}$ \\ ${ }^{1}$ Department of Surgery, Hospital of the University of Pennsylvania, Philadelphia, PA; ${ }^{2}$ Division of Endocrine and \\ Oncologic Surgery, Department of Surgery, Hospital of the University of Pennsylvania, Philadelphia, PA
}

Lymphadenectomy with retrieval of $\geq 16$ nodes at gastrectomy in gastric cancer is recommended, but the minimum retrieval number after neoadjuvant chemotherapy is unclear. Using spline regression modeling, we identified that retrieval of $\geq 23$ nodes may demonstrate a survival advantage, suggesting that lymphadenectomy should not be reduced for this population (https://doi.org/ 10.1245/s10434-021-10803-7).
FUNDING We have no relevant disclosures. No funding was provided for this study.

Publisher's Note Springer Nature remains neutral with regard to jurisdictional claims in published maps and institutional affiliations.

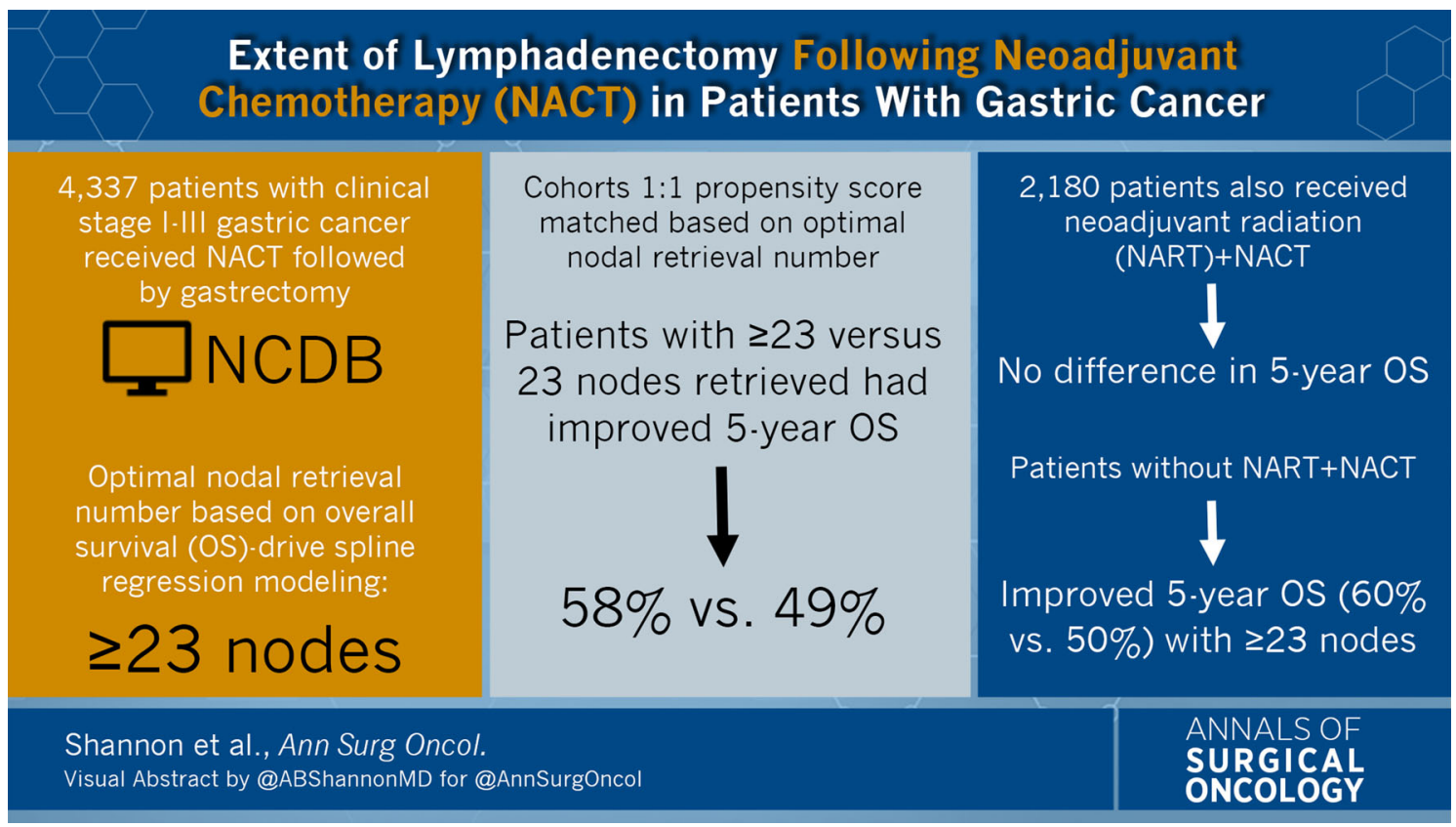

(C) Society of Surgical Oncology 2021

Published Online: 29 October 2021

A. B. Shannon, MD

e-mail: Adrienne.shannon@pennmedicine.upenn.edu 